\title{
PARAMETER EVALUATION IN HISTORICAL CONSTRUCTION: FROM SENSITIVITY ANALYSIS TO THE TEST PLANNING
}

\author{
ALFREDO CALì ${ }^{1 *}$, POLIANA DIAS DE MORAES ${ }^{2}$ AND ÂNGELA DO VALLE ${ }^{2}$ \\ ${ }^{1}$ Ph.D. Student in Civil Engineering - Department of Civil Engineering Federal University of Santa \\ Catarina (UFSC) \\ Rua João Pio Duarte Silva, Florianópolis (SC), Brazil \\ e-mail: alfredo.cali@posgrad.ufsc.br, https://orcid.org/0000-0001-8974-5866 (*corresponding author) \\ ${ }^{2}$ Associate Professor - Department of Civil Engineering Federal University of Santa Catarina (UFSC) \\ Rua João Pio Duarte Silva, Florianópolis (SC), Brazil \\ e-mail: poliana.moraes@ufsc.br \\ e-mail: angela.valle@ufsc.br
}

Keywords: H-BIM, Historical Buildings, Masonry Structures, Sensitivity Analysis.

\begin{abstract}
Uncertainties play a key role in the structural assessment in the existing buildings. They are mainly associated with materials, geometries and loads. The reduction of these uncertainties is one of the main challenges for researchers who approach this type of project. The aim of this work is the reduction of uncertainties through a sensitivity analysis. These analyses allow understanding the structural overall behaviour and they are useful to the in-situ test planning. The proposed sensitivity analysis is used as cognitive evaluation, analyzing the influences of each parameter on the structural behaviour, and as improvement assessment, evaluating the effectiveness of the intervention proposals. Furthermore, such approach reduces the impact of the experimental campaign and the intervention proposals, in terms of invasiveness, time and cost. The research is carried out through the selection of a case study, the "Quartel da Tropa" (SC), Brazil. It is used to show how the proposed approach can be applied for the structural assessment of historical buildings. The information collected was elaborated with Historical Building Information Modeling (H-BIM) and analyzed through finite element method software. The proposed research allows increasing the level of knowledge of the historical construction of the Quartel da Tropa, through the sensitivity analysis and the experimental test design of the structure. Such an approach suggests how not only the longitudinal Young's Modulus (E) and the specific weight (w) of the masonry are the main parameters to avoid significant errors in the results in terms of structural assessment. Indeed, type of wooden species, type of structural connection, different types of masonry characteristic in different structural elements must be considered.
\end{abstract}

\section{INTRODUCTION}

Uncertainty analysis [1] - mostly known as Sensitivity Analysis (SA) - is a method that deals in quantifying the uncertainty in the model output [2]. SA may be also used for other purposes [2], such as increasing the robustness of a model [3], design optimization [4], identification of 
parameters that requires further research [5] and its influence on the cracking pattern and extent, model simplification by eliminating variables [3], understanding of the model and variable interaction [6], etc. For these reasons, sensitivity analysis is a widespread method used to investigate the influence of parameters within the structural response assessment [4]. The knowledge elements - necessary for this analysis - concern the geometry of the structure, the construction details and the mechanical properties of materials [7]. As resumed by the Italian National Research Council (CNR) [7], those elements are usually obtained from (1) historicalcritical analysis aimed at reconstructing the constructive process and the subsequent modifications and events suffered over time by the building; (2) documental projects relating to the implementation and subsequent modifications; (3) geometric-structural survey referring to the overall geometry of the construction as well as that of the constructive elements, including their associated structures, quality and state of preservation of materials and building parts; (4) experimental investigations aimed at completing the information framework related to the mechanical properties of materials. In this work, the sensitivity analysis is used as a methodological step to the test planning aimed to increase the knowledge level of the historical construction through-out the use of Non-Destructive test (NDT) investigation.

This paper aims to propose an approach that allows reducing the construction uncertainties trough the understanding of the structural overall behaviour and the in-situ test planning. The combination of two methodologies - (H-BIM) [8] and the path to knowledge of historical constructions [9] - offers useful tools to the proposed goal. Through those methodologies, to carry out a sensitivity analysis is possible. It allows finding out which mechanical parameters influence the global allow reducing invasiver to know the most relevant characteristics of the The case study is the Quartel da Tropa that belong Brazil. Its analysis shows how the proposed approach can

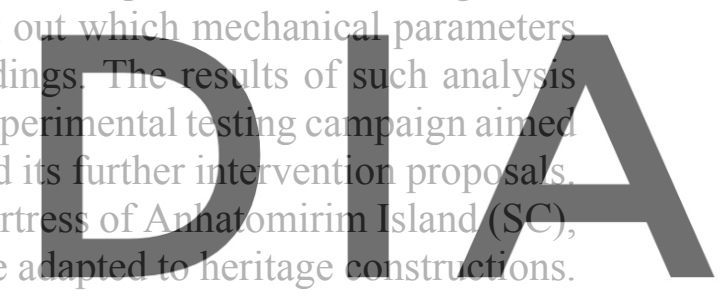

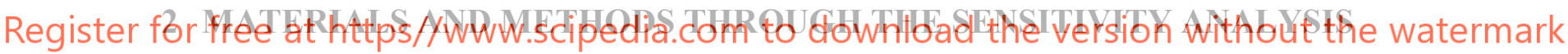

In the proposed case study, the historical-critical analysis - made by analyzing the available documental researches and the geometric-structural surveys $[10,11]-$ was useful to describe the constructive phases and to obtain a qualitative interpretation of the structural performance evolution [12]. The results of previous experimental local investigations - sonic tests, physic, and biological damages assessment, etc. - on the wooden structural elements [11] suggested their complexity - in terms of assessment of mechanical characteristics - due to the presence of several wooden species.

The knowledge factors of the structure can be distinguished between [7]: (1) factors that can be considered known in deterministic terms, i.e. with a low value of uncertainty, in absolute terms or terms of the relative sensitivity of the response; (2) factors affected by the uncertainty of aleatory type, generally associated with the intrinsic variability of characteristics of the structure; (3) factors affected by epistemic uncertainty, associated with a lack of knowledge of the structure or the mechanical behaviour of its components. As proposed in the research of CNR (2014), the epistemic uncertainties cannot be modeled as continuous variables, but they can be modeled as discrete epistemic variables [7]. For this reason, a parameter that allows describing both aleatory and epistemic uncertainties was analyzed through the sensitivity of the 
considered structural response [7]. In the proposed research, the response variation coefficient $\Delta{ }^{\prime} \mathrm{k}$ was chosen (Equation 1). This parameter was introduced by the Italian National Research Center (CNR) for the sensitivity analysis of the structural response - in terms of peak ground acceleration values that lead to the considered limit state - according to the aleatory and epistemic parameters variation [7]. In the proposed research, the authors extend the use of this parameter to evaluate structural responses in terms of static and dynamic parameters. For the static behaviour, displacements and compressive stresses were selected. For the dynamic behaviour, the first modes in each direction were chosen [6]. The parameter $\Delta$ ' was modified to show how results in the structural response differ from the average model for the aleatory (1) and epistemic (2) parameters [7]:

$$
\begin{gathered}
\Delta^{\prime}{ }_{k}=\frac{R_{k, m a x}-R_{k, m i n}}{\bar{R}}, \\
\Delta_{j}^{\prime}=2 \frac{\max \left(R_{p}\right)-\min \left(R_{p}\right)}{\max \left(R_{p}\right)+\min \left(R_{p}\right)},
\end{gathered}
$$

where $R_{k, \text { max }}$ and $R_{k, \text { min }}$ represent the values - in terms of structural response - associated with the parameter $k$, varying from its maximum to its minimum values; $\bar{R}$ is the structural response associated with the main average model, $R_{p}$ is the structural response associated with the epistemic parameter $p$, which is the number of options of the discrete variable, $p=1, m_{j}$.

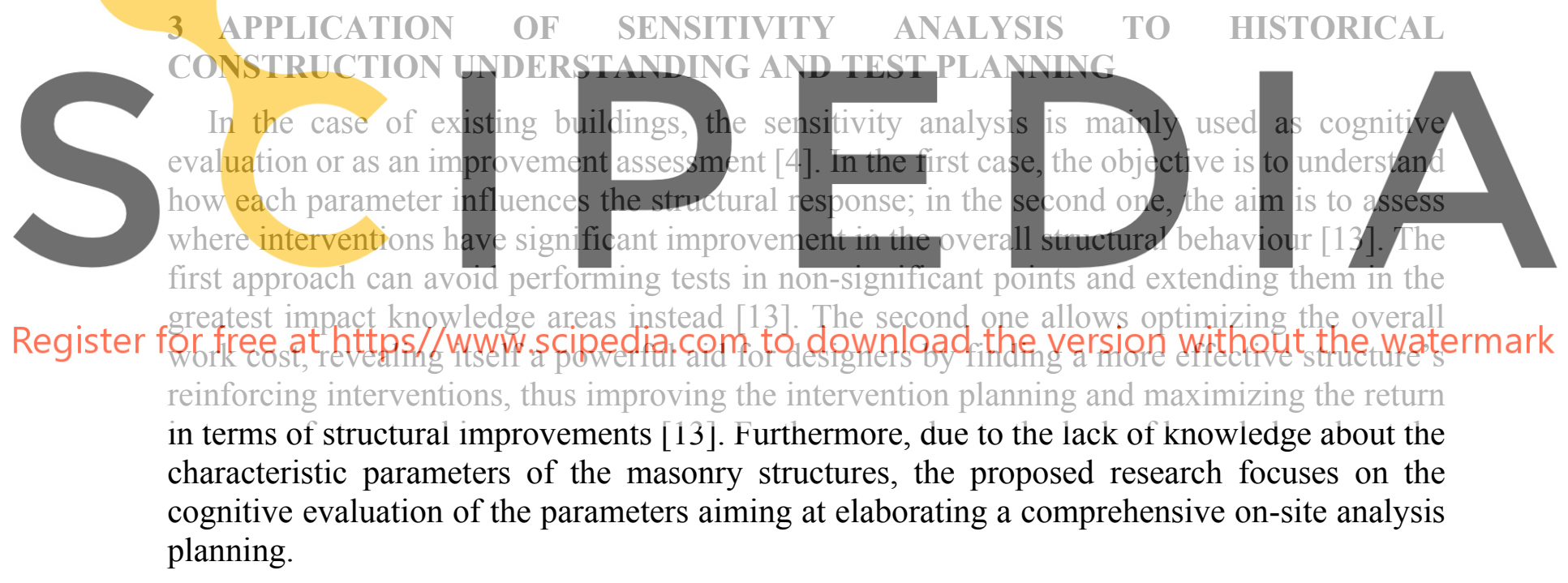

\subsection{The Quartel da Tropa: from H-BIM to FEM}

The proposed methodology was applied to the case study of the Quartel da Tropa, located in the Anhatomirim Island - Florianópolis (SC), Brazil. This $18^{\text {th }}$-century building is characterized by masonry vertical walls and wooden horizontal elements, i.e. slab and roof. It is the largest quarter among Brazilian fortifications (Fig. 1). The construction is one of the main buildings of the Fortress of Santa Cruz, located on Anhatomirim Island in the municipality of Governador Celso Ramos, State of Santa Catarina, Brazil. Designed by the Portuguese military engineer Brigadier José da Silva Paes, the building was one of the vertexes of the triangular defense system, formed together with the Fortresses of São José da Ponta Grossa and Santo Antônio de Ratones. 
a)

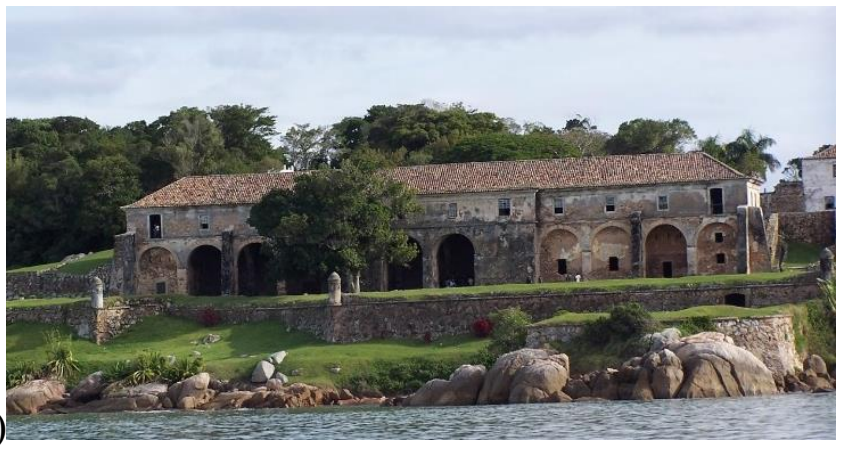

b)
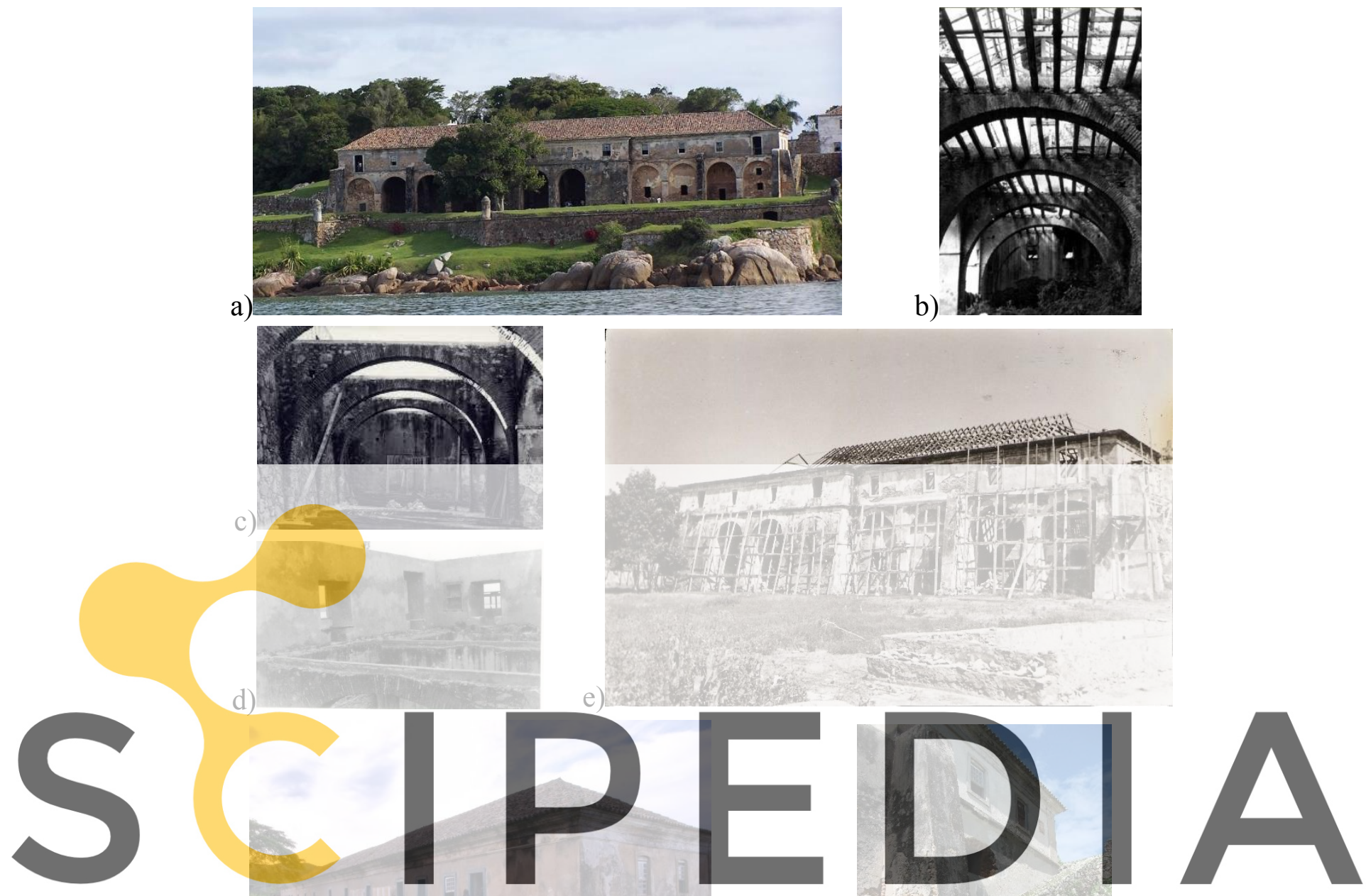

Register for free at https//www.scipedia.com to download the version without the watermark

\section{f)}

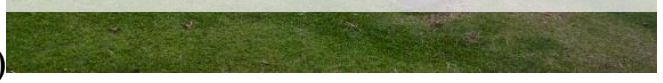

g)

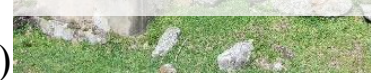

Fig. 1. Quartel da Tropa (a) in the as-current configuration after the 1970s restorations (b, c, d, e) where the simple trussed roof structure (b) were replaced with collar tie beam (e) and concrete beams (d) were introduced on the masonry arches (c); 3 sides of the structure are partially buried (f, g) [10].

Both main directions are characterized by masonry arches, at the lower levels, bearing the second level of masonry walls (Fig. 1). The structure is characterized by a central slope-shaped masonry element and buttresses (Fig. 1.e). Those interventions were probably developed to counteract horizontal loads, such as the horizontal forces caused by the soil acting on three buried lower sides of the construction (Fig. 1.f and g). The wooden horizontal structural elements have undergone modifications in the 1970s restoration interventions [10], according to a trend also found in other architectural heritage sites in Brazil [14]. The roof structure was simple trussed, with king posts and struts (Fig. 1.b). It was replaced with trusses with a collar tie beam (Fig. 1.e). In the same restoration of 1970, the wooden slabs, which were fixed in the 
masonry walls (Fig. 1.b), were substituted by simply supported beams resting on new reinforced concrete beams, applied on the masonry arches (Fig. 1.b) [10-12].

The geometrical surveys $[10,11]$ and the historical-critical analysis [12] allow defining the main characteristics of this heritage building and resuming them in a Heritage Building Information Model (H-BIM) [12]. Once previous data were implemented in a digital 3D model, the sensitivity analysis was carried out by exporting the H-BIM structural model - here created in Autodesk Revit ${ }^{\circledR}$ - in Finite Elements Method (FEM) software - Robot Structural Analysis ${ }^{\circledR}$. In the structural model, the beam elements are simplified as linear elements and the walls are simplified and represented by their middle planes. Each node of the plane and beam elements has 6 degree of freedom. The planes are meshed with thick-shell elements, which are defined by 4-nodes quadrilaterals [15]. Discrete Kirchhoff-Mindlin quadrilaterals are used with fourpoint Gaussian quadrature [16]. These elements include shear strain fields, but contrary to Mindlin elements, they prevent the problem with shear locking for thin plates [16]. Coons element with size 0.3 meter was selected as meshing methods [17], subdividing the FEM model in 158070 degrees of freedom. Furthermore, the type of connections between concrete, wooden and masonry structures was assumed as pinned, according to the visual inspection.

\subsection{Parameter modeling}

Material properties were chosen according to experimental results [11], the suggested values of the National Standards [18-20] and proved scientific researches [9, 21, 22]. Geometrical characteristics of the construction and soil parameters - obta wooden element beams were modeled as dicotylodons C20, according to the Brazilian standard ABNT NBR 7190:1997 proposed research, the and wooden parameters are assumed as epistemic (Table 1)
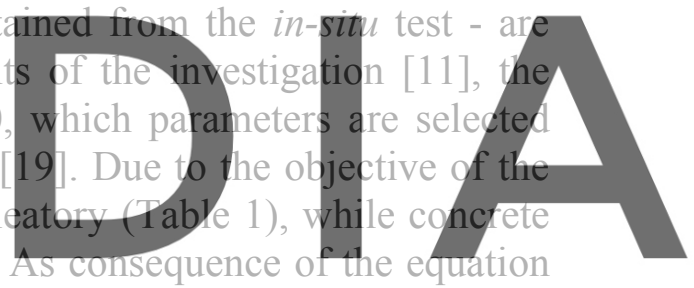
(2) the minimum number of cases to evaluate the sensitivity coefficient for epistemic Register forr freeceat in

Table 1. Deterministic and aleatory parameters of the proposed Sensitivity Analysis

\begin{tabular}{ccccccccc}
\hline & $\begin{array}{c}\text { Deterministic } \\
\text { parameters }\end{array}$ & \multicolumn{3}{c}{ Epistemic parameters } & \multicolumn{3}{c}{$\begin{array}{c}\text { Aleatory parameters of } \\
\text { masonry structures }\end{array}$} \\
\hline & Soil & Concrete 1 & Concrete 2 & Wood C20 & Wood C30 & min & average & max \\
\hline$E(\mathrm{MPa})$ & - & 18435 & 23250 & 9500 & 14500 & 1035 & 1305 & 1575 \\
$G(\mathrm{MPa})$ & - & 7681 & 9964 & 475 & 725 & 345 & 435 & 525 \\
$v$ & - & 0.20 & 0.17 & 0.27 & 0.27 & 0.10 & 0.25 & 0.5 \\
$w\left(\mathrm{kN} / \mathrm{m}^{3}\right)$ & 15.50 & 25 & 23 & 6.5 & 8 & 17 & 19 & 21 \\
$\mathrm{C}(\mathrm{kPa})$ & 14.70 & - & - & - & - & - & - & - \\
$\phi\left[^{\circ}\right]$ & 18.40 & - & - & - & - & - & - & - \\
\hline
\end{tabular}

Regarding the evaluation of the epistemic parameters, 9 cases are investigated. In the average model, the connections are supposed as pinned, meaning that the rotations $R_{y}$ and $R_{z}$ are allowed. For the type of connection assessment, in case 1, all the connections are supposed as fixed, while, in case 2, only rotations $R_{y}$ are allowed. Since, case 2 shown no significant modification in terms of structural response in cases 3, 4 and 5, fixed connections are supposed in the roof, slab, and reinforced concrete (RC) beams, respectively. In case 6 , wooden elements 
are defined as C30, according to the Brazilian standard ABNT NBR 7190:1997 [19]. Similarly, in case 7, RC beams are assumed with different material characteristics according to the Brazilian standard ABNT NBR 6118:2007 [20] (Table 1). In cases 8 and 9, the hypotheses of different masonry characteristics are investigated, where the properties of buttresses and arches are defined according to the Italian standard Circolare 617/09 suggestions for brick masonry type, $\mathrm{E}=1500 \mathrm{MPa}, \mathrm{G}=500 \mathrm{MPa}$ and $\mathrm{w}=18 \mathrm{kN} / \mathrm{m}^{3}[18]$.

\subsection{Analysis definition}

In this work, two types of linear analysis are proposed: static and modal analysis. In the modal analysis, the contribution of the static loads - including the soil actions. Hence, the evaluation of the first modal frequencies in each direction offers an initial approach to the understanding of the global stiffness (Fig. 2.a and b). The linear static analyses allow a first understanding of distributions of loads and structural responses, in terms of stresses and displacement [21] (Fig. 2.c and .d). The structural analyses are carried out in Robot Structural Analysis ${ }^{\circledR}$ (Equations 3 and 4) for the solution of linear equation systems:

$$
\begin{gathered}
{[\mathrm{K}]\{\mathrm{U}\}=\{\mathrm{F}\},} \\
\left([K]-\omega_{i}^{2}[M]\right)\left\{\varphi_{i}\right\}=0,
\end{gathered}
$$

where $[K]$ is the stiffness matrix, $\{U\}$ and $\{F\}$ are displacement and force vectors, $[M]$ is the mass matrix of the structure, $\omega_{i}$ is the natural frequency referred to the eigenvector $\left\{\varphi_{i}\right\}$.
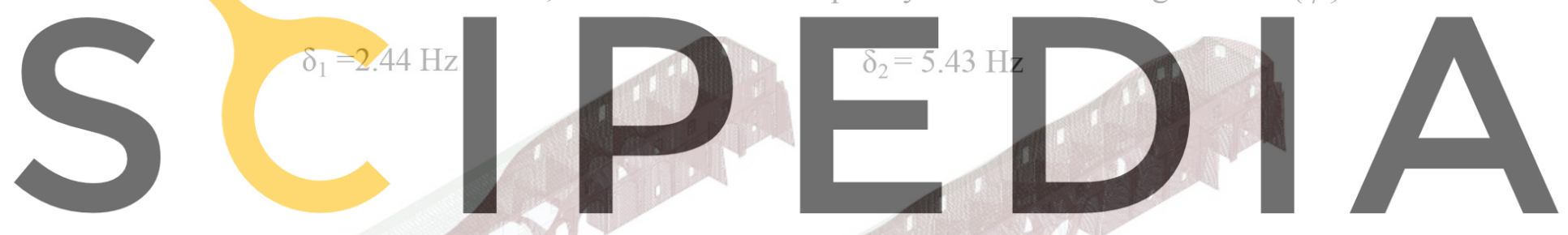

Register for free at https//www.scipedia.com to download the version without the watermark

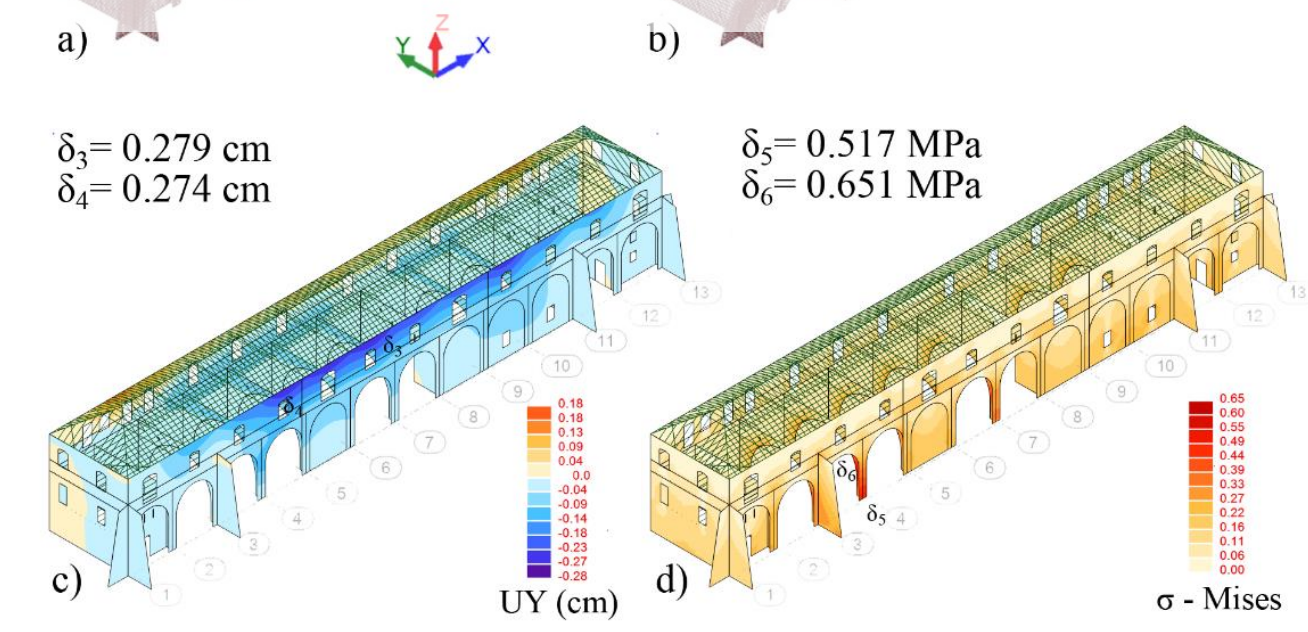

b)

Fig. 2. First vibrational modes in transversal $\left(\delta_{1}\right)\left(\right.$ a) and longitudinal $\left(\delta_{2}\right)($ b) directions. Top out-of-plane displacements $\delta_{3}$ between axes $6^{\text {th }}$ and $7^{\text {th }}$ and $\delta_{4}$ between axes $4^{\text {th }}$ and $5^{\text {th }}(\mathrm{c})$. Mises stresses at the base of the column $\delta_{5}$ and the springing line of $\operatorname{arch} \delta_{6}$ in the $4^{\text {th }}$ axis (d). 


\section{RESULTS AND DISCUSSION}

The interpretation of the proposed analyses suggests the control point selection where the results of the sensitivity analysis will be recorded. In terms of total displacements, the introduction of the central masonry element reduced the strains in the structure, concentrating the stresses on the side parts of the façade [12]. Indeed, stress peak values are reached in the column base and the springing line the $4^{\text {th }}$ axis arch (Fig. 2.d). Instead, out-of-plane displacement peak values are reached on top of walls of the left part of the northeast façades (Fig. 2.c). For those reasons, the variations of the parameters in the sensitivity analysis were recorded in such control points, as defined in Fig. 2.

\subsection{Sensitivity analysis}

The sensitivity analysis was carried out to assess how the characterization of each one of the selected parameters affect the global structural behaviour [181. Parameters $\delta_{1}$ and $\delta_{2}$ are obtained as a preliminary evaluation of the overall stiffness in each direction, in terms of first vibrational modal frequencies, while parameters from $\delta_{3}$ and $\delta_{6}$ describe the static behaviour of the structure, in terms of displacements and stresses (Fig. 2).

Table 2. Response variations $\delta_{\mathrm{i}}$ according the sensitivity analysis of the aleatory and epistemic parameters

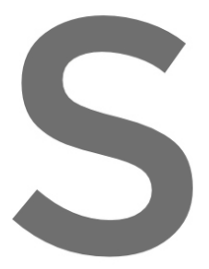

\begin{tabular}{ccc}
\hline Aleatory parameters & $\delta_{1}[\mathrm{~Hz}]$ & $\delta_{2}[\mathrm{~Hz}]$ \\
\hline Base & 2.4420 & 5.4334 \\
$\mathrm{E}_{\min }$ & 2.2158 & 4.9735 \\
$\mathrm{E}_{\max }$ & 2.6347 & 5.8379 \\
$\mathrm{G}_{\min }$ & 2.4224 & 5.4011 \\
$\mathrm{G}_{\max }$ & 2.4562 & 5.4566 \\
$V_{\min }$ & 2.4271 & 5.4828 \\
\hline
\end{tabular}

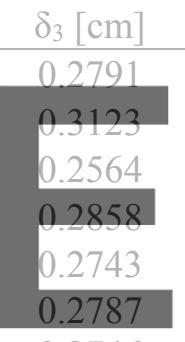

0.2746

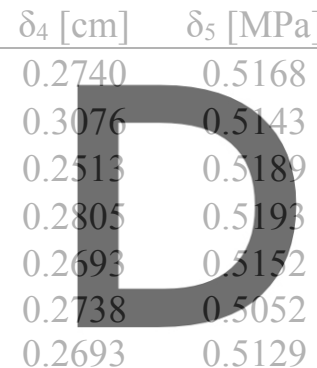

0.5129
$\delta_{6}[\mathrm{MPa}]$

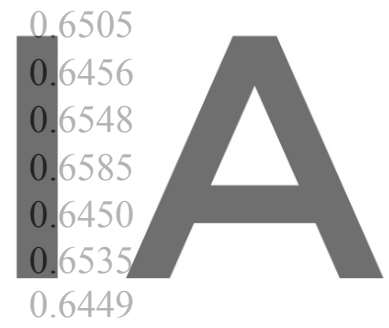

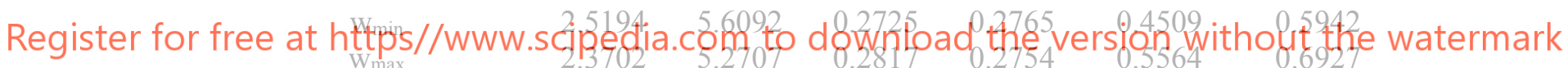

\begin{tabular}{ccccccc}
\hline Epistemic parameters & $\delta_{1}$ & $\delta_{2}$ & $\delta_{3}$ & $\delta_{4}$ & $\delta_{5}$ & $\delta_{6}$ \\
\hline Case 1 & 2.4461 & 5.6863 & 0.2347 & 0.2294 & 0.5162 & 0.6527 \\
Case 2 & 2.4357 & 5.6540 & 0.2776 & 0.2712 & 0.5165 & 0.6502 \\
Case 3 & 2.4572 & 5.5383 & 0.2346 & 0.2293 & 0.5173 & 0.6539 \\
Case 4 & 2.4274 & 5.5383 & 0.2788 & 0.2736 & 0.5156 & 0.6493 \\
Case 5 & 2.4461 & 5.4603 & 0.2794 & 0.2746 & 0.5169 & 0.6506 \\
Case 6 & 2.4466 & 5.6388 & 0.2433 & 0.2393 & 0.5199 & 0.6620 \\
Case 7 & 2.4536 & 5.4502 & 0.2784 & 0.2737 & 0.5163 & 0.6482 \\
Case 8 & 2.4439 & 5.4403 & 0.2790 & 0.2709 & 0.4868 & 0.6129 \\
Case 9 & 2.4676 & 5.5502 & 0.2742 & 0.2708 & 0.4984 & 0.6957 \\
\hline
\end{tabular}

The improvement assessment of the possible intervention was evaluated according to the sensitivity analysis of the epistemic factors. It was obtained considering the quality of the connections between different structural elements. This evaluation (Table 3 and Fig. 3) shows how the main differences - in terms of out-of-plane displacements (Table 3 and Fig. 3) - are obtained considering the structure connections as fixed, mainly in roof structure $\Delta^{\prime}{ }_{3}=0.20$, $\Delta^{\prime}{ }_{4}=0.15$. In other terms, interventions developed to create stiffer connections in the roof 
elements could improve the structural overall box-behaviour. As expected, the main variations were obtained due to the uncertainty of Young's Modulus $(E)$ (Table 3 and Fig. 3), related to the structure stiffness. The variation of the Shear Modulus $(G)$ the Poisson's ratio $(v)$ does not affect considerably the overall structure stiffness. Instead, the assessment of the specific weight of the masonry $(w)$ influences the results of the structural model global behaviour.

The type of wooden beam also affects the static behaviour of the construction - in terms of displacements - and a further investigation on the wooden physic and mechanical parameters should be done. The RC beam type and connections, instead, seems to have a very low influence on the global behaviour of the structures, meaning also that their introduction in the restoration intervention is questionable. Furthermore, since the constructive evolution of the Quartel shows that material stratification, two assumptions were investigated. Case 8 and 9 were developed considering that different material properties were used in the buttresses and the arches, respectively.

Table 3. Response variation coefficients $\Delta_{k}^{\prime}$ according to the sensitivity analysis of the aleatory parameters

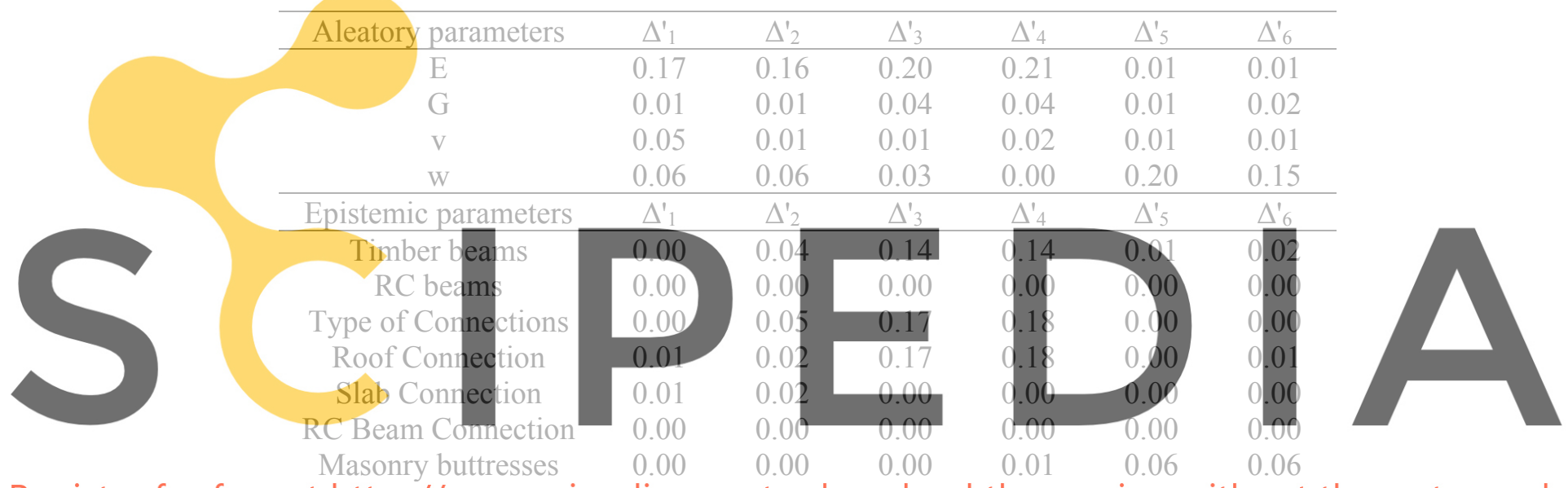

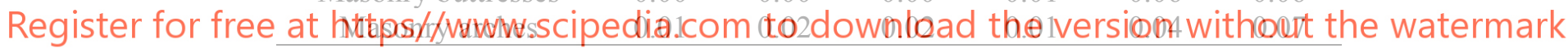

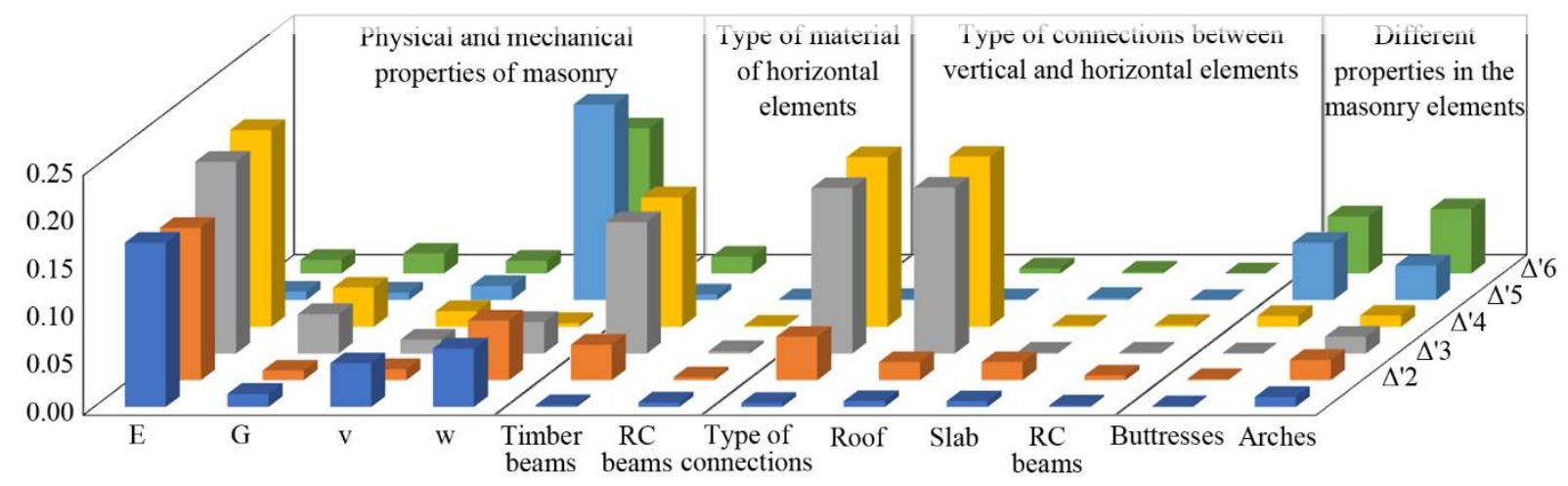

Fig. 3. Sensitivity coefficients of structural responses according to the aleatory parameters Young's Modulus ( $E$, $G)$, Poisson's ratio $(v)$, average specific weight of masonry $(w)$; Sensitivity coefficients of structural responses according to the epistemic parameters: timber and RC type of beams, quality of the connections, the types of materials in the different masonry elements 


\subsection{In-situ test planning design}

An experimental investigation planning focused on these main characteristics allows reducing costs and time [23]. As shown in the analysis of the wooden structures [11], visual inspection has a key role in the preliminary assessment of the structural characteristic of the construction. This tool has allowed observing some damages in the structure of the Quartel $d a$ Tropa. The base of the column of the $4^{\text {th }}$ axis shows an extended crack pattern in the external part of the masonry (Fig. 4.a and Fig. 4.b). The structural element of the column - situated in the $4^{\text {th }}$ axis - has a high value of out-of-plane displacements and stresses (Fig. 2), confirming the asymmetrical character of the structure. Furthermore, describing the damage patterns by geometrical surveys is useful to collect such information for further analysis. The use of orthophotos improves the damage pattern surveys recording the current state of the construction, simplifying the process of data collection in the knowledge path of the heritage building. The H-BIM offers the possibility to improve the previous tools through the implementation of laser scanning, which permits a better geometrical description and representation of the historical construction. A laser scanning campaign should be done to describe the displacement pattern of the structural elements [8]. Such an approach is also available to be used for the calibration of the parameters of the structural model, comparing the laser scanning recorded displacements with the structural analysis results [8]. In the case of Quartel da Tropa, the laser scanning could confirm - or deny - the results of the developed structural and sensitivity analysis.
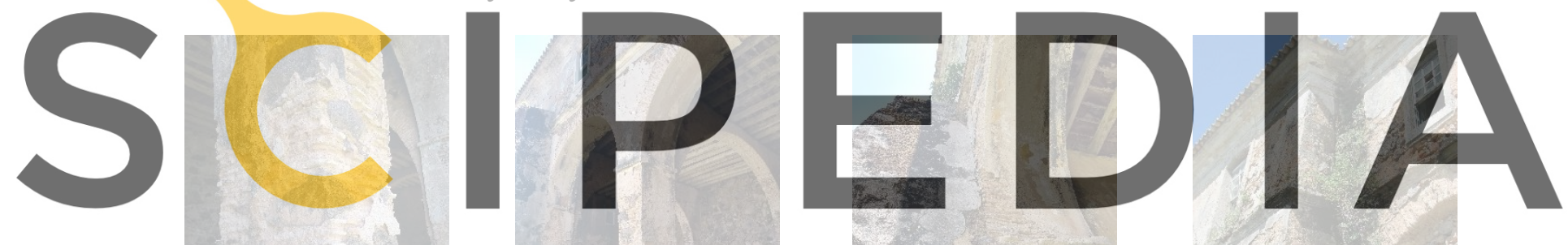

Register for free at https//www.scipedia.com to

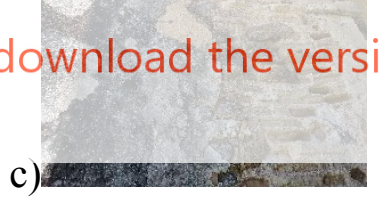

b)

c)

d)

Fig. 4. Damages in the column of the $4^{\text {th }}$ axis of the structure $(a, b)$, connection between column and buttresses (c) and connection of the central slope-shaped masonry with the main façade (d)

Furthermore, the identification of vibration modes should be carried out through Ambient vibration tests [3]. It will improve the process of calibration of the structural model, also through the aleatory and epistemic parameter evaluation. In the case of historical buildings, this type of experimental tests is adequate for its non-destructive characteristic and because it describes the global behaviour of the structure [23]. The set-up of the accelerometers should be done according to the results obtained from the modal analysis (Fig. 5). Two biaxial accelerometers should be installed in the lateral parts of the ground floor - near the northeast façade - to measure the longitudinal and transversal displacements at the ground level. Similarly, two biaxial accelerometers should be set in the upper floor to measure the displacement variations in the two main directions. In the middle point $-7^{\text {th }}$ axis - another biaxial accelerometer could be installed - with one uniaxial accelerometer on the opposite façade - to detect any differential 
displacement by the façades in the two directions. It should record even some possible torsional effect due to the asymmetry of the structure. In the $4^{\text {th }}$ and $10^{\text {th }}$ axes, unidirectional accelerometers could be set to assess the behaviour of the building in the points where structural analysis showed higher values of out-of-plane displacements. Such a set-up could be used to develop a structural health monitoring system to assess the structural behaviour modifications according to the particular environment of the Quartel, considering winds, humidity and temperature variations (Fig. 5). Once the vibration modes are obtained from the experimental results, the sensitivity analysis proposed in this research could be compared and improved according to the experimental vibration modes and the out-of-plane displacement survey obtained from the laser scanning. A process of manual tuning of the main parameters could be adopted to assess the aleatory and the epistemic parameters of the structure proposed in the further research $[3,4]$.

Since the geometrical depth of the retaining wall of the considered structure is unknown, indirect sonic tests could assess the geometry of such a structural element (Fig. 5) [23]. Sonic tomography tests [23] could evaluate the consistency of the masonry elements and the effectiveness of the connections of the structural element added in the different constructive phases, e.g. the connection between the buttresses and the masonry column (Fig. 4.c) or the central slope-shape masonry element (Fig. 4.d). In the case that previous NDT test results need further analysis, another uncertainty could be introduced and investigated. Carrying out single and double flat-jack tests [23] - considered as minor destructive tests - allows understanding if the mechanical parameters of the different masonry elements can be simplified in a single type of masonry, as was chose tests define locally the Modulus E, which was a) Non-destructive in-situ test, ground floor
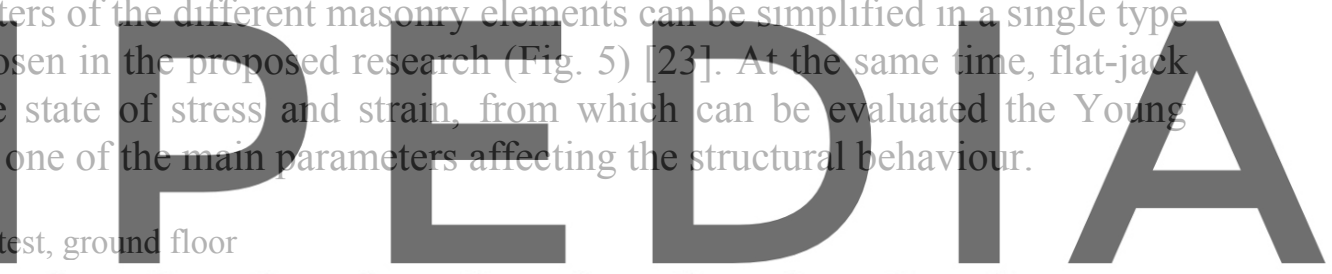

Register for free at https//www.scipedia.com to download the version without the watermark

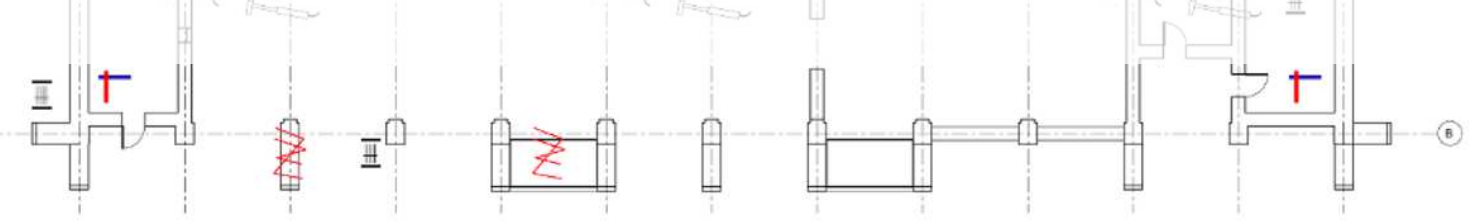

b) Non-destructive in-situ test, first floor

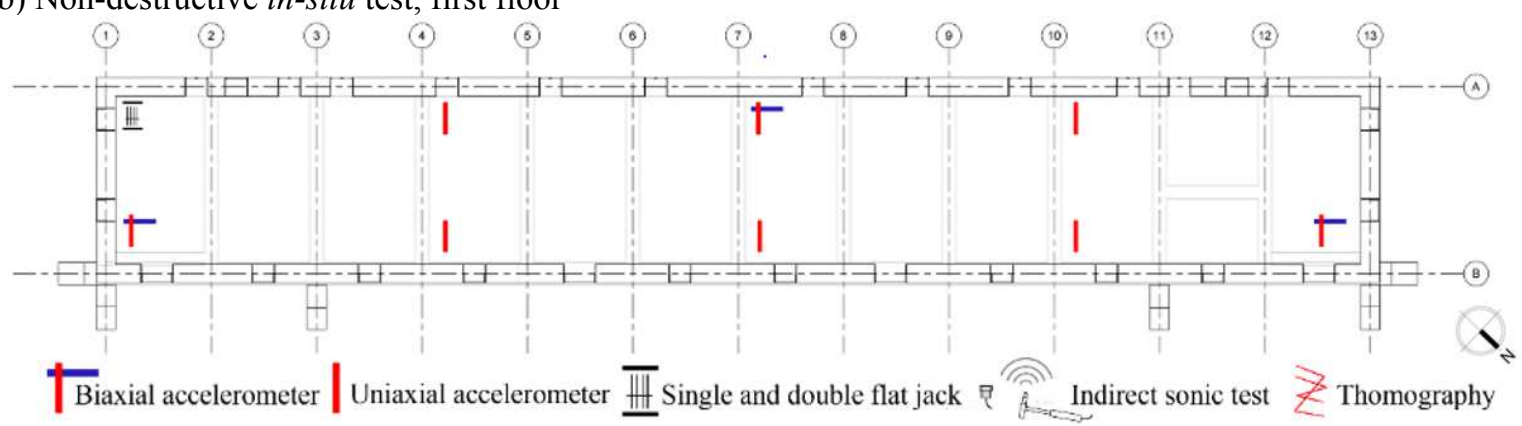

Fig. 5. Experimental test set-up: accelerometer configuration for the modal parameter assessment and the health monitoring, and other non-destructive or minor destructive tests 


\section{CONCLUSION}

This research confirms how the structural behaviour of historical buildings depends on the level of knowledge of the material parameters and structural behaviour in terms of stress, deformations, and stiffness. The results of the proposed research allow concluding:

- the methodology proposed in this research allows increasing the level of knowledge of the historical construction of the Quartel da Tropa, through the sensitivity analysis and the experimental test campaign of the structure;

- the cognitive evaluation allows improving the test planning, focusing on the assessment of the main parameters localizing the impact of the experimental test on the relevant structural elements. In the proposed case study, the sensitivity analysis shows how not only the longitudinal Young's Modulus (E) and the specific weight (w) of the masonry are the main parameters to avoid significant errors in the results in terms of structural assessment. Indeed, type of wooden species, type of structural connection, different types of masonry characteristic in different structural elements must be considered;

- the analyses show that current construction configuration has an asymmetrical structural behaviour. In terms of stress and displacement, the left part of the building suffers the higher stresses and out-of-plane displacements. In those points, some pathology manifestations were observed;

- regarding the improvement assessment, the quality of the connections of wooden elements of the roof structure influences the out-plane displacements, meaning that interventions on such connections could be necessary to increase the box-behaviour.

Acknowledgements. This project has been funded with the support of the European Commission. This publication reflects the view only of the author, and the Commission cannot be held responsible for any use which may be made of the information contained therein - ELARCH program (Project Ref. number 552129-EM-1-2014-1-IT-ERA MUNDUSEMA21). This work was also supported by the Coordenação de Aperfeiçoamento de Pessoal de Nivel Superior - Brazil (CAPES) - Finance Code 001.

\section{REFERENCES}

[1] Saltelli, A., Tarantola, S., Campolongo, F., and Ratto, M. Sensitivity analysis in practice: a guide to assessing scientific models, Vol. I (2004). New York: Wiley.

[2] Boscato, G., Russo, S., Ceravolo, R., and Fragonara, L. Z. Global sensitivity-based model updating for heritage structures. Comp. Aid. Civ. Infr. Eng. (2015) 30(8): 620-635.

[3] Gentile, C., Saisi, A., and Cabboi, A. Structural identification of a masonry tower based on operational modal analysis. Int. J. Archit. Herit. (2015) 9(2): 98-110.

[4] Asgari, B., Osman, S. A., and Adnan, A. Sensitivity analysis of the influence of structural parameters on dynamic behaviour of highly redundant cable-stayed bridges. Adv. Civ. Eng. (2013).

[5] Cattari, S., Lagomarsino, S., Bosiljkov, V., and D'Ayala, D. Sensitivity analysis for setting up the investigation protocol and defining proper confidence factors for masonry buildings. Bull. Earthq. Eng. (2015) 13(1): 129-151.

[6] Carvalho, J., Ortega, J., Lourenço, P. B., Ramos, L. F., and Roman, H. Safety analysis of modern heritage masonry buildings: Box-buildings in Recife, Brazil. Eng. Struct. (2014) 
80: $222-240$.

[7] CNR, DT. 212 2013. Istruzioni per la Valutazione Affidabilistica della Sicurezza Sismica di Edifici Esistenti. Consiglio nazionale delle ricerche, 14 (2014).

[8] Antonopoulou, S., and Bryan, P. Historic England BIM for Heritage: Developing a Historic Building Information Model. Swindon: Historic England (2017). Retrieved March 10, 2019.

[9] Directive of the Prime Minister, Italian Guidelines for evaluation and mitigation of seismic risk to Cultural Heritage, Directive. Rome, Italy, 2007.

[10] Tonera R., Fortalezas de Santa Catarina a Caminho de tornarem-se Patrimônio Mundial. Florianópolis, Brazil (2010). Information available at http://fortalezas.org/

[11] Terezo, R. F. Avaliação das estruturas de madeira do quartel da tropa da fortaleza da ilha de Anhatomirim. (2005). GIEM, Grupo Interdisciplinar de Estudos da Madeira. Florianópolis: UFSC.

[12] Calì, A., do Valle, Â., and de Moraes, P. D. Building Information Modeling and Structural Analysis in the Knowledge Path of a Historical Construction. In: R. Aguilar et al. (Eds.): Structural Analysis of Historical Constructions, RILEM Bookseries 18 (2019), pp. 2071-2079.

[13] Lagomarsino, S., Penna, A., Galasco, A., and Cattari, S. TREMURI program: an equivalent frame model for the nonlinear seismic analysis of masonry buildings. Eng. Struct. (2013). 56: 1787-1799.

[14] Pereira, R. L. Estruturas de coberta da Arquitetura religiosa em Pernambuco tipologia, patologia e intervenções. Rev. Bras. Arquem., Rest. Cons. (2007) 1(6): 332 - 337. AERPA Editor, 2007.

[15] Ho-Le, K. Finite element mesh generation methods: a review and classification. Comput. Des. (1988) 20(1): 27-38.

[16] Katili, I. A new discrete Kirchhoff-Mindlin element based on Mindlin-Reissner plate theory and assumed shear strain fields - Part I : An extended DKT element for thick-plate bending analysis. Int. J. Numer. methods Eng., (1993) 36(11): 1859-1883.

[17] S. A. Coons, Surfaces for computer aided desing of space form. USA (1967) (No. MACTR-41). Massachusetts Inst. of Tech. Cambridge Project MAC.

[18] Circolare, 617/09. Istruzioni per l'applicazione delle Norme Tecniche per le Costruzioni di cui al DM 14 gennaio 2008. Gazzetta Ufficiale Della Repubblica Italiana.

[19] Associação Brasileira de Normas Técnicas. ABNT NBR 7190: Projeto de estruturas de madeira (1997).

[20] Associação Brasileira de Normas Técnicas. ABNT NBR 6118: Projeto de estruturas de concreto-procedimento. ABNT. (2007).

[21] Roca, P., Cervera, M., and Gariup, G. Structural analysis of masonry historical constructions. Classical and advanced approaches. Arch Comput Meth Eng. (2010) 17(3): 299-325.

[22] Rocco Lahr, F. A., Christoforo, A. L., Chahud, E., Branco, L. A. M. N., Battistelle, R. A., and Valarelli, I. D. Poisson's ratios for wood species for structural purposes. Adv. Mater. Res. (2015) 1088: 690-693. Trans Tech Publications Ltd.

[23] Binda, L., and Saisi, A. Non destructive testing applied to historic buildings: The case of some Sicilian Churches. Hist. Constr. (2001): 29-46. 